\title{
APLIKASI PENGAJARAN TAUHID DALAM KELUARGA SEBAGAI SOLUSI MENGATASI PERMASALAHAN KENAKALAN REMAJA
}

\author{
Adam Sugiarto ${ }^{\text {a,1, }}$, Rachmatullah Rusli b,2, Mudzakir ${ }^{c, 3}$, Fathudin Ali d,4, Nurjaya e,5, \\ $a, b, c, d, e$ S1 Akuntansi, Fakultas Ekonomi, Universitas Pamulang* \\ ${ }^{1}$ dosen01597@unpam.ac.id, ${ }^{2}$ dosen01198@unpam.ac.id, ${ }^{3}$ dosen01596@unpam.ac.id, \\ ${ }^{4}$ dosen01821@unpam.ac.id, ${ }^{5}$ dosen01605@unpam.ac.id.
}

\begin{abstract}
Abstrak
Berbagai permasalahan sosial yang muncul dalam kehidupan bermasyarakat, terutama di kalangan remaja yang dipengaruhi oleh perkembangan teknologi yang begitu cepat dari waktu ke waktu, dunia remaja menjadi sasaran empuk dari pengaruh buruk teknologi ini karena semua hal dapat dengan mudah mereka dapatkan dari gadget mereka, mulai dari terbuka luasnya dunia pertemanan sampai mudahnya akses-akses terhadap konten-konten yang negative seperti pornografi, radikalisme yang kemudian dapat menyeret para remaja kepada pergaulan bebas, narkoba, tawuran dan seterusnya. Minimnya pengetahuan orangtua dalam memahami dan mengatasi permasalahan tersebut membuat mereka tidak mampu untuk mengarahkan putra-putri mereka agar terhindar dari berbagai pengaruh negative pergaulan dan teknologi, Atas dasar keinginan untuk berbagi dan memberikan solusi terhadap hal tersebut maka PKM ini dilakukan dengan tujuan untuk meningkatkan pemahaman dan pengetahuan orangtua dalam mengatasi dan membentengi putra-putri mereka dari pengaruh negatif pergaulan dan teknologi dengan menguatkan pendidikan tauhid di dalam keluarga.
\end{abstract}

Kata Kunci: Pengajaran, Tauhid, Remaja, Keluarga.

\section{Abstract}

Various social problems that arise in social life, especially among adolescents who are influenced by the rapid development of technology from time to time, the world of adolescents is an easy target of the bad influence of this technology because they can easily get everything from their gadgets, starting from the open. the breadth of the world of friendship to easy access to negative content such as pornography, radicalism, which can then drag teenagers to promiscuity, drugs, brawl and so on. The lack of knowledge of orangutans in understanding and overcoming these problems makes them unable to direct their children to avoid various negative influences of association and technology. On the basis of the desire to share and provide solutions to this, this PKM is carried out with the aim of increasing understanding and knowledge of parents in overcoming and fortifying their children from the negative influence of socialization and technology by strengthening tauhid education in the family.

Keywords: Teaching, Tawheed, Youth, Family. 
PENDAHULUAN

Pengabdian Kepada Masyarakat merupakan bagian dari Tri Dharma Perguruan Tinggi selain pendidikan dan pengajaran serta penelitian dan pengembangan, dengan dilaksanakannya Tri Dharma Perguruan Tinggi berupa Pengabdian Kepada Masyarakat diharapkan para dosen mampu untuk berkontribusi dalam memberikan arahan dan bimbingan kepada masyarakat sesuai dengan kapasitas ilmu yang mereka miliki.

Masyarakat memiliki peranan yang sangat penting dalam pendidikan baik sebagai sumber pelaksana maupun sebagai pengguna hasil pendidikan. Menurut UU RI nomor 20 Tahun 2003 tentang Sistem Pendidikan Nasional, komite sekolah/madrasah adalah lembaga mandiri yang beranggotakan orangtua/wali peserta didik, komunitas sekolah, serta tokoh masyarakat yang peduli pendidikan. Keluarga sebagai potret dari sebuah masyarakat adalah bagian yang tak kalah pentingnya dalam dunia pendidikan bahkan dalam istilah pendidikan Islam disebutkan bahwa "al-Umm madrastu alUla" bahwa ibu adalah tempat yang pertama di mana anak-anak mendapatkan pembelajaran. lingkungan keluarga atau orangtua memiliki peran yang sangat penting dalam pendidikan anak sehingga apa yang nampak dari perilaku seorang anak merupakan hasil dari asuhan dan pendidikan orangtua serta lingkungan keluarganya.

Keluarga merupakan pencetak sekaligus pembentuk generasi bangsa dan agama. Generasi yang memiliki kepribadian individu yang kaffah (paripurna). Pribadi individu yang demikian merupakan pribadi yang menggambarkan terwujudnya keseluruhan esensi manusia secara kodrati, yaitu sebagai makhluk individu, makhluk sosial, makhluk bermoral, dan makhluk yang bertuhan. Citra pribadi yang seperti itu sering disebut sebagai manusia paripurna (insan kamil) atau pribadi yang utuh, sempurna, seimbang dan selaras (Wiyani, 2012:6). Begitu pula dengan pendidikan agama Islam dengan tauhid yang menjadi landasannya. Pendidikan Agama terutama tauhid dimaksudkan untuk peningkatan potensi spiritual dan membentuk seseorang agar menjadi manusia yang beriman dan bertakwa kepada Tuhan Yang Maha Esa dan berakhlak mulia.

Keluarga menjadi lingkungan pertama dalam memberikan pendidikan tauhid sekaligus membentuk ketauhidan pada diri seorang anak, orangtua adalah unsur utama bagi tegaknya tauhid dalam keluarga, sehingga setiap orang wajib memiliki tauhid yang baik, sehingga dapat membekali anak-anaknya dengan ketauhidan dan materi-materi yang mendukungnya, di samping anak dapat melihat orangtunya sebagai teladan yang memberikan pengetahuan sekaligus 
pengalaman dan pengarahan (Ahmad Tafsir, 2002:8)

Berbagai permasalahan sosial yang sering muncul dalam kehidupan keluarga, terutama di kalangan remaja, mulai dari pergaulan bebas, narkoba, tawuran dan seterusnya semestinya menyadarkan kita akan pentingnya pendidikan agama terutama tauhid dalam kehidupan keluarga, ketauhidan akan membawa seseorang kepada kebebasan yang sebenarnya yang menuju kepada ketundukan kepada Allah SWT semata. Semakin kurang pemahaman tauhid seseorang, maka semakin rendah pula akhlak, watak dan kepribadiannya. Oleh karena itu, pentingya menanamkan nilai tauhid kedalam jiwa sehingga terbentuk pribadi yang kokoh dalam menghadapi berbagai persoalan kehidupan dan terhindar dari pengaruh-pengaruh negatif yang tidak diinginkan. (Sayid Sabiq, 2006:8), Sebaliknya, jika akidah tauhid seseorang telah kokoh dan mapan (established), maka terlihat jelas dalam setiap amaliahnya. Setiap konsep yang berasal dari Islam, pasti akan diterima secara utuh dan dengan lapang dada, tanpa rasa keberatan dan terkesan mencari-cari alasan hanya untuk menolak.inilah sikap yang dilahirkan dari seorang muslim sejati. (Rasyid, 2000:16)

Akhirnya, dapat disimpulkan bahwa pendidikan tauhid dalam keluarga sangatlah penting dan harus segera dilakukan oleh para orang tua, karena fungsinya yang sangat besar dalam membentuk pribadi muslim yang benar, dan bertakwa kepada Allah SWT, yang dihiasai dengan akhlak dan perilaku positif, sehingga anak-anak yang bertauhid juga akan melakukan hal-hal yang positif. Hal-hal yang dapat bermanfaat baik untuk dirinya, keluarganya, masyarakatnya, agamanya, bahkan dunia. Aktivitas yang timbul dari anak yang bertauhid hanyalah mencari ridho Allah SWT, bukan mencari sesuatu yang bersifat duniawi.

Atas dasar keinginan untuk berbagi dan memberikan solusi terhadap hal tersebut maka PKM ini dilakukan dengan tujuan untuk meningkatkan pemahaman dan pengetahuan para orangtua yang berada di perumahan AlFalah 3 Tangerang Selatan, Banten tentang bagaimana mengaplikasikan pendidikan tauhid dalam keluarga.

\section{METODE}

Pengabdian kepada Masyarakat ini dilaksanakan di perumahan Al-Falah 3 Tangerang Selatan, Banten pada tanggal 24 Nopember 2019 Kegiatan ini diikuti oleh jama'ah majlis ta'lim warga yang dikelola oleh RW (Rukun Warga) yang berada di sekitar lokasi tersebut. Kegiatan dilakukan dengan metode ceramah dan diskusi dengan rincian kegiatan sebagai berikut: 
Tabel 1. Rincian Kegiatan PKM

\begin{tabular}{|l|l|}
\hline Jadwal & \multicolumn{2}{|c|}{ Kegiatan } \\
\hline Sesi 1 & Sosialisasi pengertian konsep \\
$19.00-$ & pendidikan dalam Islam. \\
19.30 & Ceramah dan tanya jawab tentang \\
\hline Sesi & pentingnya pendidikan tauhid dalam \\
$19.30-$ & keluarga \\
20.00 & Ceramah dan tanya jawab tentang \\
\hline Sesi 3 & Penerapan Pedidikan Tauhid dalam \\
$20.00-$ & Keluarga \\
20.30 & Ceramah dan tanya jawab tentang \\
\hline Sesi 4 & problematika dalam menanamkan \\
$20.30-$ & nilai tauhid pada anak \\
21.00 & Ceramah dan tanya jawab tentang \\
\hline Sesi 5 & bagaimana Rasulullah SAW \\
$21.00-$ & menanamkan tauhid pada keluarganya \\
21.30 &
\end{tabular}

Pendekatan dilakukan dengan mencari permasalahan orangtua dalam memberikan pendidikan tauhid dalam keluarga dan memberi solusi. Kegiatan dimulai dengan pemaparan dari para pemateri yang terdiri dari 5 orang dosen yang menyampaikan berbagai teori yang berkaitan dengan pendidikan tauhid dalam keluarga dan penerapannya. Permasalahan orangtua diketahui ketika proses tanya jawab. Dari permasalahan yang muncul disusun hal-hal penting untuk kemudian diberikan solusi oleh para pemateri.

\section{HASIL DAN PEMBAHASAN}

Sebagai bagian dari tujuan pendidikan islam, tauhid adalah inti dari pendidikan Islam. Karena prinsip pendidikan tauhid adalah pemenuhan kebutuhan fitrah manusia. Islam merupakan agama tauhid. Selain itu, tauhid merupakan ajaran Al-Qur'an yang paling mendasar, di mana penyampaian ajaran tauhid merupakan misi utama rasul yang diutus Allah SWT. Mereka diperintahkan mengajak masyarakat masingmasing untuk menyembah Allah dan jangan menyekutukannya dengan apapun, disamping itu mereka sendiri telah terlebih dahulu menyembah Allah berdasarkan keyakinan dan pengetahuan tentang tauhid, lebih dari sekedar dalil dalil yang mereka ungkapkan kepada kaumnya. perkataan tauhid sangat erat hubungannya dengan kata wahid (satu atau esa), dalam bahasa arab sebagai istilah yang dipergunakan dalam membahas ketuhanan. Tauhid merupakan keyakinan akan keesaan tuhan (Allah). Allah itu berjumlah, berdzat bersifat dan berbuat esa (unicum). Artinya jumlah-Nya, DzatNya, Sifat-Nya dan perbuatan Nya adalah satu-satu satunya, tidak ada dua nya, lain dari pada yang lain tidak sama dan tidak ada persamaannya dengan yang ada. Kata tauhid berasal dari Bahasa Arab, masdar dari kata "wahhada" (وحد) “yuwahhidu" (يوحد) "tauhidan" (نوحيدا), secara etimologis tauhid berarti peng-esa-an. Maksudnya, I'tikad atau keyakinan bahwa Allah SWT adalah Esa/Tunggal/Satu (Amir, 2016:68). Tauhid sangat berkaitan erat dengan keimanan, jiwa yang beriman merupakan jiwa yang tidak 
cenderung kepada tindakan tindakan dzalim (aniaya), karena pada dasarnya iman yang benar (al-iman ash shahih) tidak wajar dicampur dengan kedzaliman, karena kedzaliman tidak mungkin tercampur dengan iman, karena iman memiliki kecenderungan pada kebaikan, keadilan, kedamaian, keselamatan, dan kepada penunaian hakhak seperti yang di ajarkan oleh agama

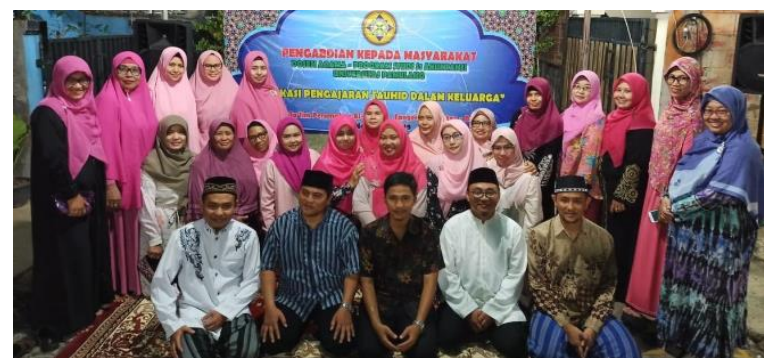
sebagaimana diabadikan menurut al-Qur'an dan hadits.

Gambar 1. Peserta PKM, Mahasiswa dan Narasumber

Al-Qur'an juga mengajak manusia menganut prinsip tauhid dengan cara menyebutkan akibat-akibat positif bertauhid, dalam bentuk ganjaran kebaikan dan pahala, baik di dunia maupun di akhirat. Sebaliknya, Al- Qur'an juga menerangkan akibat-akibat negatif dari sikap penentangan prinsip tauhid baik dalam bentuk akibat yang berupa hukuman-hukuman di dunia maupun siksaan diakhirat. Perbuatan syirik manusia akan melahirkan balasan terburuk dan terjahat di akhirat. Dalam menegaskan prinsip tauhid, Allah berfirman "Maka ketahuilah, bahwa Sesungguhnya tidak ada Ilah (sesembahan
Tuhan) selain Allah dan mohonlah ampunan bagi dosamu dan bagi (dosa) orang-orang mukmin, laki-laki dan perempuan. dan Allah mengetahui tempat kamu berusaha dan tempat kamu tinggal" (QS. Muhammad : 19).

Adapun di antara metode yang digunakan dalam memberikan pengajaran tauhid kepada anak-anak adalah memperdengarkan kalimat-kalimat tauhid, memberikan keteladanan, pembiasaan, memberikan nasehat dan melakkukan pengawasan. memperdengarkan kalimatkalimat tauhid dimulai saat anak tersebut dilahirkan ke dunia. Karena sesungguhnya bayi yang baru lahir pendengarannya sudah berfungsi, sehingga ia akan langsung memberikan reaksi terhadap suara. Telinga akan segera berfungsi setelah ia lahir, meskipun ada perbedaan antara bayi yang satu dengan yang lain.

Keteladanan sebagai salah satu metode yang penting dalam pengajaran, sebagai sumber pendidikan Islam juga pendidikan tauhid dalam keluarga, al-Qur'an telah memberikan statemen tentang keteladanan sebanyak tiga kali yakni dalam surat $\mathrm{Al}$ Ahzab ayat 21 dan surat Al Mumtahanah ayat 4 dan 6. Nabiyullah Ibrahim AS dan Nabi Muhammad SAW dijadikan sebagai profil keteladanan. (Hamdani, 2002:45) Keteladanan merupakan sesuatu yang patut 
untuk ditiru atau dijadikan contoh teladan dalam berbuat, bersikap dan berkepribadian.

Secara psikologis seorang anak cenderung meneladani orang tuanya, karena adanya dorongan naluriah untuk meniru. Kualitas agama seorang anak serta ketauhidannya sangat tergantung kepada orang yang terdekat dengan mereka yakni orang tua. Kepribadian anak akan terbentuk dari teladan yang ia tiru sejak awal kehidupannya dalam keluarga. Orangtua merupakan sentral figur bagi anak dalam keluarga, semua yang dilakukan orangtua dalam Quantum teaching disebutkan bahwa semuanya berbicara, bahkan mimik wajahpun menyampaikan informasi bagi anak. Semuanya menjadi sumber anak untuk belajar, sehingga jiwa ketauhidan harus selalu terpancar dari setiap wajah orang tua. Kepribadian yang menunjukkan bahwa orang tua hanya takut dan tunduk kepada Allah SWT, muncul dalam setiap aktivitas yang ada dalam keluarga. Metode keteladanan merupakan satu tehnik pendidikan yang efektif dan sukses dalam pendidikan Islam.

Pembiasaan adalah metode yang sangat efektif untuk anak-anak, karena daya rekam dan ingatan anak yang masih kuat sehingga pendidikan penanaman nilai moral, terutama ketauhidan ke dalam jiwanya sangat efektif untuk dilakukan. Potensi dasar yang dimiliki anak serta adanya potensi lingkungan dibentuk melalui pembiasaan-pembiasaan yang memerlukan proses serta waktu yang panjang. Nashih Ulwan menjelaskan bahwa landasan awal dalam metode pembiasaan adalah "fitrah" atau potensi yang dimiliki oleh setiap anak yang baru lahir, yang diistilahkan oleh beliau dengan "keadaan suci dan bertauhid murni”. Sehingga dengan pembiasaan diharapkan dapat berperan untuk menggiring anak kembali kepada tauhid yang murni tersebut. (Setiawan, 2017:6). Ketauhidan akan tumbuh melalui latihanlatihan dan pembiasaan.

Nasehat adalah salah satu cara untuk menjelaskan tentang semua hakekat. Termasuk dalam menyampaikan dan menjelaskan materi-materi pendidikan tauhid dalam keluarga. Nasehat harus dimulai juga sejak anak masih kecil, selain sebagai sarana pendidikan tauhid juga sebagai dorongan dan motivasi anak untuk belajar berbicara. Kemampuan bahasa anak akan diiringi oleh kemampuan otaknya juga. Maksudnya ketika ia mendengarkan sebuah nasehat ia akan merekam setiap kosa kata yang ia dengar dalam memorinya, serta akalnya juga mencoba memahami setiap kosa kata sampai kalimat yang ia dengar. Oleh karena itu bahasa yang digunakan orang tua haruslah sederhana dan jelas. 
Orangtua dapat menggunakan media penunjang dalam memberikan nasehat seperti buku-buku cerita para rasul atau cerita-cerita teladan atau video-video yang memuat cerita para rasul dan juga cerita tentang ketauhidan lainnya. Sehingga pendidikan nasehat yang disampaikan meliputi seluruh potensi yang dimiliki anak mulai pendengaran dan penglihatan. Orang tua harus menjadi jendela informasi anakanaknya. Sehingga dibutuhkan pengetahuan dan wawasan yang luas agar dapat memberikan informasi dengan baik dan benar.

\section{Berikutnya adalah perluhnya} pengawasan dalam menanamkan nilai-nilai tauhid kepada anak-anak. dalam membentuk akidah anak memerlukan bimbingan serta adanya pengawasan dari orangtua, sehingga keadaan anak selalu terpantau. Secara universal prisip-prinsip Islam mengajarkan kepada orang tua untuk selalu mengawasi dan mengontrol anak-anaknya. Hal ini dilandaskan pada nash Al Qur'an dalam surat At-Tahrim ayat 6. Fungsi seorang pendidik harus mampu melindungi diri, keluarga dan anak-anaknya dari ancaman api neraka. Fungsi tersebut dapat dilaksanakan dengan baik jika pendidik melakukan tiga hal yakni memerintahkan, mencegah dan mengawasi. Bukan anak-anaknya saja yang ia awasi tetapi juga dirinya agar tidak melakukan kesalahan yang menyebabkan dirinya terancam api neraka. Bagaimana ia melindungi keluarganya dari api neraka jika ia tidak mampu menjaga dirinya sendiri.

Maksud dari pengawasan yaitu orangtua memberikan teguran pada anaknya jika melakukan kesalahan atau perbuatan yang dapat mengarahkannya kepada pengingkaran ketauhidan. Pengawasan juga bermakna bahwa orangtua siap memberikan bantuan jika anak memerlukan penjelasan serta bantuan untuk memahami dan melatih dirinya dengan kebiasaan-kebiasaan yang diajarkan kepadanya.

Dari hasil kegiatan ini dapat diidentifikasikan bahwa bertambahnya pengetahuan serta pemahaman peserta terhadap pendidikan tauhid didalam keluarga serta adanya motivasi dan keinginan yang kuat untuk mengaplikasikannya dalam kehidupan sehari-hari sebagai usaha untuk membentengi putra-putri mereka dari pengaruh buruk yang ada di sekeliling mereka.

\section{KESIMPULAN}

Pendidikan tauhid merupakan unsur yang sangat penting sebagai solusi untuk mengatasi kenakalan remaja, Dari kegiatan pengabdian pada masyarakat ini dapat 
disimpulkan bahwa adanya peningkatan terhadap pengetahuan dan pemahaman orangtua yang berada di perumahan Al-Falah 3, Tangerang Selatan tentang bagaimana mengaplikasi pengajaran tauhid dalam keluarga. Adanya kesadaran dan semangat orangtua yang berada di perumahan Al-Falah 3, Tangerang Selatan untuk mengaplikasikan pendidikan tauhid dalam keluarga semakin meningkat. Mengingat besarnya manfaat kegiatan pengabdian pada masyarakat ini, maka selanjutnya perlu diadakan kegiatan serupa di tempat yang berbeda dengan materi yang sama sehingga aplikasi pendidikan tauhid dalam keluarga benar-benar difahami oleh setiap orangtua yang menginginkan anak-anaknya memiliki tauhid yang kokoh sehingga dapat membentengi kehidupan mereka kelak dari pengaruh-pengaruh yang dapat merugikan kehidupan mereka baik di dunia maupun di akhirat.

\section{REFERENSI}

Amir, M. (2016). Membumikan Konsep Pendidikan Qurani. Makasar: Alauddin University Press

Hamdani, Ahmad Firjon (2019). Konsep Pendidikan Akhlak pada Kisah Nabi Ibrahim dalam al-Quran. ([Tesis]). Malang: Program Pascasarjana Universitas Islam Maulana Malik Ibrahim Malang
Hidayat, Angga dkk. (2020). Peningkatan Ketrampilan Dasar Matematika Dan Bahasa Inggris Sebagai Upaya Dalam Menghadapi Tantangan Era Revolusi Industri 5.0. Abdimisi Vol. 1 No. 1 Desember.

Rasyid, D. (2000). Islam dalam Berbagai Dimensi. Jakarta: Gema Insani Press.

Sabiq, Sayid (2006). Aqidah Islamiyah. Jakarta: Robani Press.

Setiawan, Agus. (2017). Konsep Pendidikan Tauhid dalam Keluarga Perspektif pendidikan Islam. Jurnal Ilmiah Educasia Vol. 2 No. 1, 2017

Tafsir, Ahmad. (2002). Pendidikan Agama Dalam Keluarga. Bandung: PT Remaja Rosdakarya

Wiyani, Novan Ardy dan Barnawi. (2012). Ilmu Pendidikan Islam Rancang Bangun Konsep Monokotomik-Holistik. Yogyakarta: Ar-Ruzz Media 